\title{
Comentário
}

\section{Prevenção da dependência da nicotina: uma prioridade de saúde pública}

Quando a história da saúde pública for escrita daqui a alguns séculos, as gerações futuras recordarão admiradas o fato de termos permitido que um produto, causador da morte de metade de seus consumidores, tivesse seu uso incentivado e fosse vendido tão livremente por tanto tempo. Talvez em alguns séculos, o uso do tabaco fique restrito a uma minoria de dependentes, fazendo com que seja claramente percebido, dentro de seu contexto histórico, como um dos maiores assassinos da humanidade. Peto estima que aproximadamente 100 milhões de pessoas morreram em decorrência da dependência da nicotina no século XX e, pela tendência atual, 1 bilhão de pessoas morrerão em virtude de seu uso no século XXI. ${ }^{1}$

Como as tendências de mortalidade pela dependência da nicotina sucedem as de consumo em mais de 40 anos, ainda não se sabe a extensão dessa epidemia no Brasil, mas podem-se fazer estimativas que não são nada animadoras. É talvez surpreendente que, dada a gravidade do problema, não existam no país dados coletados sistematicamente sobre a prevalência dessa dependência.

Um levantamento nacional realizado em 1989 revelou uma prevalência de $40 \%$ para adultos do sexo masculino e $25 \%$ do sexo feminino (prevalência total de 33\%). Em torno da mesma época, um outro estudo feito em São Paulo, com indivíduos entre 25 e 34 anos de idade, indicou índices de $54 \%$ e $20 \%$, respectivamente, para homens e mulheres. ${ }^{2}$ São números muito elevados e indicam que a mortalidade devido a neoplasias, doença pulmonar crônica e doença cardíaca será muito elevada - e crescente - por, ao menos, 30 anos ou mais, a menos que uma ação efetiva seja tomada imediatamente.

As estimativas de mortalidade também apresentam alguns problemas. No Brasil, apenas cerca de $70 \%$ dos óbitos são registrados, e há razões para suspeitar que muitas mortes por neoplasias em indivíduos idosos são diagnosticadas de forma equivocada (Peto, comunicação pessoal). Segundo um estudo realizado em 1990, 8,7\% das mortes eram causadas pelo tabagismo. Esse valor pode ser baixo (na Europa é de 14\%), mas se for levado em consideração, pelo menos 81 mil pessoas morrem todos os anos no Brasil em decorrência do tabagismo (acredita-se que os valores reais sejam muito maiores).

Felizmente, existem medidas a serem tomadas para reduzir o número de mortes devido a essa dependência . O ministro da Saúde, José Serra, encaminhou uma proibição de publicidade ao Congresso e ao Senado brasileiros que, se implementada correta e rigorosamente, salvará muitos milhares de vidas no país. A iniciativa de Serra é louvável, mas ele precisará de apoio e de determinação para resistir às tentativas da indústria do tabaco de atenuar a própria lei ou sua implementação. A indústria do tabaco, conhecida por não manter vínculos com a verdade, fará muitas alegações, como a de que proibir a publicidade não funciona. Não é verdade. Após uma revisão recentemente realizada pelo Banco Mundial e pela Organização Mundial da Saúde, concluiu-se que proibir a publicidade do tabaco reduz o consumo, mas acrescentou-se que essas proibições precisam ser abrangentes e devem ser parte de um programa extensivo de controle da dependência da nicotina. ${ }^{4}$

A indústria usará de todo seu poder para atenuar a lei, suas interpretações ou sua implementação, e buscará encontrar isenções ou diferimentos. No Reino Unido, o primeiro escândalo de um governo de grande aprovação popular ocorreu quando, depois que o presidente da Fórmula 1 fez uma doação de R \$ 3 milhões (depois devolvida) ao Partido Trabalhista, o esporte recebeu sete anos de isenção. A proibição à publicidade precisa ser uma medida ampla e diligente, e a esse respeito o Brasil fez melhor que o Reino Unido ao limitar a isenção da Fórmula 1 em apenas dois anos.

A indústria do tabaco pode alegar que muitos ficarão desempregados. Esse é um aspecto que deve ser considerado com seriedade e em longo prazo, e esforços devem ser feitos para realocar os agricultores de plantações de tabaco em outros setores agrícolas, uma providência negligenciada pelos países europeus. Mas o Brasil também possui uma grande indústria manufatureira, e um estudo econômico realizado no Reino Unido demonstrou que a redução do consumo de tabaco aumenta o número de postos de trabalho. Isto porque os ex-fumantes tendem a gastar seu dinheiro em produtos e serviços que requerem mais mão-de-obra que a fabricação de cigarros, na qual a mão-de-obra humana foi substituída por maquinário moderno. ${ }^{5}$

Outra alegação é a de que, como a venda de cigarros é permitida por lei, deve também ser permitido incentivar seu consumo, e uma proibição cercearia o direito constitucional de liberdade de expressão. De fato, pouco direitos são absolutos, e o direito à liberdade de expressão comercial não pode suplantar o direito à saúde. Poucos países possuem uma constituição que, por exemplo, permite manifestações racistas, e a constituição brasileira reconhece a necessidade de impor tais limites.

Um outro argumento é que o uso do cigarro constitui uma escolha pessoal. De fato, a Organização Mundial da Saúde, o Ministério da Saúde dos Estados Unidos, a Associação Americana de Psiquiatria, o Colégio Real de Médicos do Reino Unido e muitas outras autoridades de saúde consideram o uso 
do cigarro como uma dependência química — por sinal, uma das mais poderosas. ${ }^{6}$

A experiência de muitos países revela que, quando o governo faz frente à indústria do tabaco e prioriza a saúde de seus cidadãos, o ônus de doenças e mortes relacionadas à dependência da nicotina pode ser revertido. Esperamos que a proibição de publicidade seja o início de uma série de medidas para reduzir a prevalência dessa dependência e a mortalidade decorrente dela. Essas medidas devem incluir impostos mais elevados e programas educativos para a população, outras restrições ao uso do cigarro em locais públicos, regulamentação mais restrita de produtos do tabaco, dos níveis de alcatrão e nicotina e dos rótulos, e a provisão de mais assistência e tratamento para milhões de pessoas que querem parar de fumar mas não conseguem fazê-lo por conta própria. Por fim, ao início da elaboração dessas observações, nos surpreendemos em perceber que o Brasil não possui levantamentos estatísticos confiáveis e regulares sobre o número de fumantes e sua mortalidade.
Enquanto esses dados não forem coletados de forma regular, não será possível medir o desempenho de programas de controle da dependência da nicotina, inclusive o sucesso da iniciativa corajosa e inovadora de proibir a publicidade.

\section{Agradecimentos}

A Montezuma Pimienta Ferreira por seus comentários, que foram de muito proveito na elaboração deste artigo.

\author{
Martin Raw \\ aEscola de Medicina Guy's King e St. Thomas e \\ Universidade de Londres \\ Ronaldo Laranjeira \\ Universidade Federal de São Paulo \\ Escola Paulista de Medicina
}

\section{Referências}

1. Peto R, Lopez AD. Future worldwide health effects of current smoking patterns. In: Koop CE, Pearson CE, Schwarz MR, editors. Critical issues in global health. San Francisco (CA): Jossey-Bass; 2001. p. 154-61.

2. Lopez A. Tobacco or health. A global status report. Geneva: World Health Organization; 1997.

3. Daudt AW et al. Tobacco-related diseases: a 21-year study (19701990) of the mortality rate in the state of Rio Grande do Sul, Brazil. J Smoking Related Dis 1993;4(3):155-63.

4. Saffer H. Tobacco advertising and promotion. In: Jha P, Chaloupka F, editors. Tobacco Control in Developing Countries. Oxford/ New York: World Bank; 2000. p. 215-36.

5. Buck D, Godfrey C, Raw M, Sutton M. Tobacco and jobs. The impact of falling consumption on employment in the UK. London/ York: Society for the Study of Addiction \& Centre for Health Economics; 1995.

6. Nicotine addiction in Britain. A report of the Tobacco Advisory Group of the Royal College of Physicians. London: RCP; 2000. 